\title{
Power Generation Using Piezoelectric Material
}

\section{Nayan $\mathbf{H R}^{*}$}

American International University, Dhaka, Bangladesh

\begin{abstract}
In last few years low power electronic devices have been increased rapidly. The devices are used in a large number to comfort our daily lives. With the increase in energy consumption of these portable electronic devices, the concept of harvesting alternative renewable energy in human surroundings arise a new interest among us. In this project I try to develop a piezoelectric generator. That can produce energy from vibration and pressure available on some other term (like people walking ). This project describes the use of piezoelectric materials in order to harvest energy from people walking vibration for generating and accumulating the energy. This concept is also applicable to some large vibration sources which can find from nature. This project also represents a footstep of piezoelectric energy harvesting model which is cost effective and easy to implement.
\end{abstract}

Keywords: Piezoelectric sensor; Full-wave bridge rectifier; Lead acid battery; Load (LED and USB charger)

\section{Introduction}

Now a day's energy is one of the most important issues around the world. Especially in Bangladesh energy crisis is a big problem. Renewable energy sources can be a great media to solve this energy crisis problem in Bangladesh. As we know natural resources will finish one day. That's why researchers are trying to introduce substitute energy sources from nature. That must be green and not harmful for the environment. Energy harvesting is defined as capturing minute amounts of energy from one or more of the surrounding energy sources. Human beings have already started to use energy harvesting technology in the form of windmill, geothermal and solar energy. The energy came from natural sources, termed as renewable energy. Renewable energy harvesting plants generate $\mathrm{kW}$ or MW level power; it is called macro energy harvesting technology. Moreover, micro energy also can produce from those natural sources that are called micro energy harvesting. Micro energy harvesting technology is based on mechanical vibration, mechanical stress and strain, thermal energy from furnace, heaters and friction sources, sun light or room light, human body, chemical or biological sources, which can generate $\mathrm{mW}$ or $\mu \mathrm{W}$ level power. Micro power supply needs is increasing greatly with time as our technology is moving to the micro and nanno fabrication levels. Our discussion on this is based on generating micro energy from vibration and pressure using piezoelectric material.

\section{Piezoelectric Sensor}

This day most of the research in the energy field is to develop sources of energy for future. It is time to find renewable surceases of energy for the future. Piezoelectric materials are being more and more studied as they turn out to be very unusual materials with very specific and interesting properties. In fact, there materials have the ability to produce electrical energy from mechanical energy for example they can convert mechanical behavior like vibrations in to electricity. Such devices are commonly referred to as energy harvesters and can be used in applications where outside power is unavailable and batteries are not a feasible option. While recent experiments have shown that these materials could be used as power generators, the amount of energy produced is still very low, hence the necessity to optimize them.

Piezoelectric materials have two properties that are define as direct and converse effect. Direct effect is the property of some materials to develop electric change on their surface when mechanical stress is exerted on them, while converse effect is the property of some materials to develop mechanical stress when an electric charge is induced [1].

\section{Advantages:}

1. Very high frequency response.

2. Self-generating, so no need of external source.

3. Simple to use as they have small dimensions and large measuring range.

4. Barium titanate and quartz can be made in any desired shape and form. It also has a large dielectric constant. The crystal axis is selectable by orienting the direction of orientation.

\section{Disadvantages}

1. It is not suitable for measurement in static condition.

2. Since the device operates with the small electric charge, they need high impedance cable for electrical interface.

3. The output may vary according to the temperature variation of the crystal.

4. The relative humidity rises above $85 \%$ or falls below $35 \%$, its output will be affected. If so, it has to be coated with wax or polymer material.

\section{Full-Wave Bridge Rectifier}

Full-bridge rectifier is commonly used as rectifier circuits to convert the AC output of a piezoelectric into a DC voltage. The rectifying circuits consist of 4 diodes. The voltage needs to rectify due to the need for constant supply of voltage light up the series of LED placed in parallel [2].

*Corresponding author: Nayan HR, American International University, Dhaka Bangladesh, Tel: 880 2-8815386; E-mail: nayanhabib@yahoo.com

Received April 03, 2015; Accepted May 21, 2015; Published May 31, 2015

Citation: Nayan HR (2015) Power Generation Using Piezoelectric Material. J Material Sci Eng 4: 171. doi:10.4172/2169-0022.1000171

Copyright: (c) 2015 Nayan HR. This is an open-access article distributed under the terms of the Creative Commons Attribution License, which permits unrestricted use, distribution, and reproduction in any medium, provided the original author and source are credited. 


\section{Lead Acid Battery}

Battery an array of electrochemical cells for electricity storage, either individually linked or individually linked and housed in a single unit. An electrical battery is a combination of one or more electrochemical cells, used to convert stored chemical energy into electrical energy. Batterystandby power applications. Miniature cells are used to power devices such as hearing aids and wristwatches; larger batteries provide standby power for telephone exchanges or computer datacenters.

\section{Primary battery}

Primary batteries can produce current immediately on assembly. Disposable batteries are intended to be used once and discarded. These are most commonly used in portable devices such as in alarm and communication circuits where other electric power is only intermittently available. Disposable primary cells cannot be reliably recharged, since the chemical reactions are not easily reversible and active materials may not return to their original forms. Battery manufacturers recommend against attempting recharging primary cells.

\section{Secondary battery}

Secondary batteries must be charged before use; they are usually assembled with active materials in the discharged state. Rechargeable batteries or secondary cells can be recharged by applying electrical current, which reverses the chemical reactions that occur during its use. Devices to supply the appropriate current are called chargers or rechargers $[3,4]$.

\section{Loads}

The USB charging converter convert $12 \mathrm{~V}$ dc to $5 \mathrm{~V}$ dc. It consist of IC-AD84064, capacitor, diode and LED. All of this component convert voltage to charge device like as Mobile, IPod, Tab, MP3 devices, and charger light etc. All the rechargeable equipment will be charged [5].

\section{Some common mistakes}

Though piezoelectric material has the property of converting mechanical energy into electrical energy but developing piezoelectric generators is challenging because of their poor source characteristics (high voltage, low current, high impedance) and relatively low power output [6]. In the past these challenges have limited the development and application of piezoelectric generators. The main limitation of our project is I could not amplify the current or power from source to charge our battery faster with less steps. And another one is I could not find better piezoelectric sensor in our region. That's why I use buzzer as piezoelectric sensor, which has a little amount of piezo crystal material in its surface $[7,8]$. And the thickness of these sensors is much less. So these sensors could break by people pressure. But, finally I managed with our mechanical structure to give the strength and got maximum output as $\mathrm{mW}$ range (Figures 1-7).

\section{Result and finding}

In 1 square $\mathrm{ft}$. I used 12 piezo sensor.

As piezo sensors power generating varies with different steps, get

Minimum voltage $=1 \mathrm{~V}$ per step

Maximum voltage $=10.5 \mathrm{~V}$ per step

I took an average of $50 \mathrm{Kg}$ weight pressure from single person.

Considering the steps of a $50 \mathrm{Kg}$ weighted single person, the average calculation is:

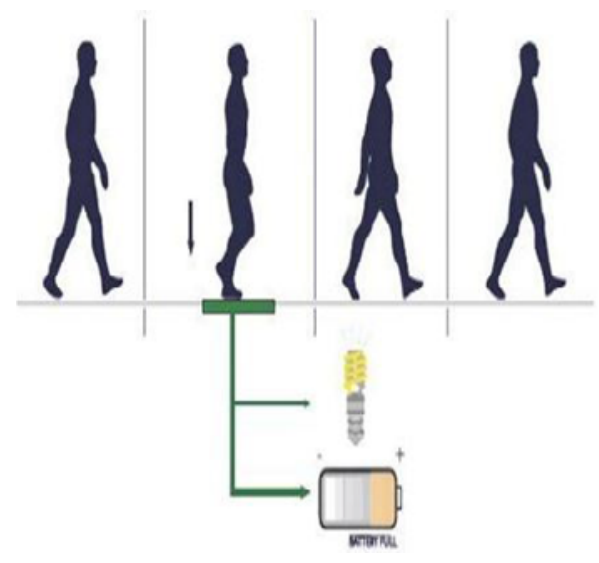

Figure 1: Footstep energy harvesting.
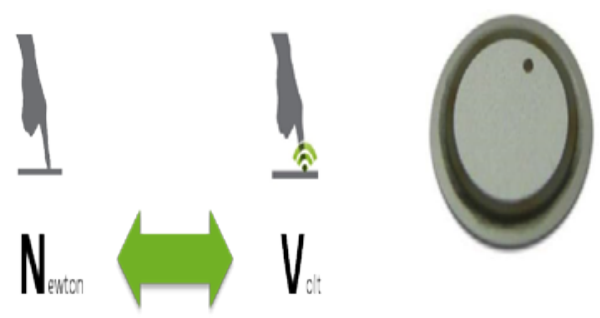

Figure 2: How to work piezoelectric sensor.

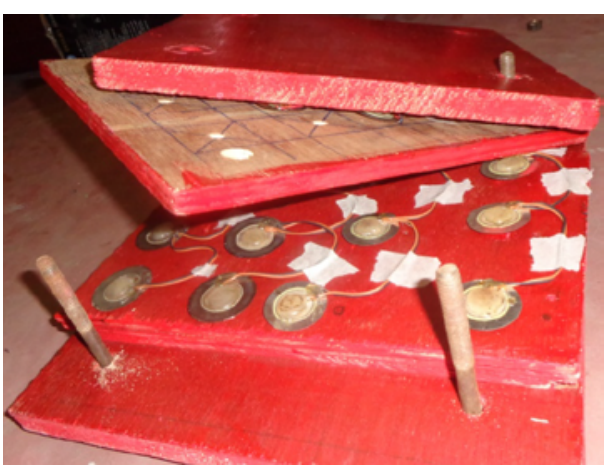

Figure 3: Design our project piezoelectricsensor.

It takes 800 steps to increase $1 \mathrm{~V}$ charge in battery.

So, to increase $12 \mathrm{~V}$ in battery total steps needed

$=(12 \times 800)$

$=9600$ steps

As I will implement our project in a populated area where foot step as source will available, I took an average of 2 steps in 1 second.

For 9600 steps time needed

$=9600 /(60 \times 2)$

$=80$ minutes. (Approximately) 


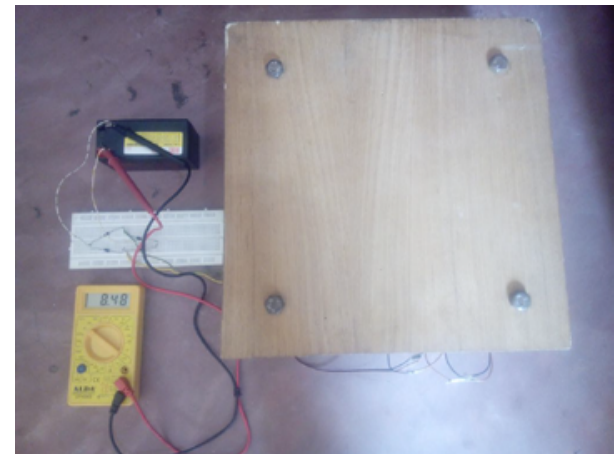

Figure 4: Charging model.

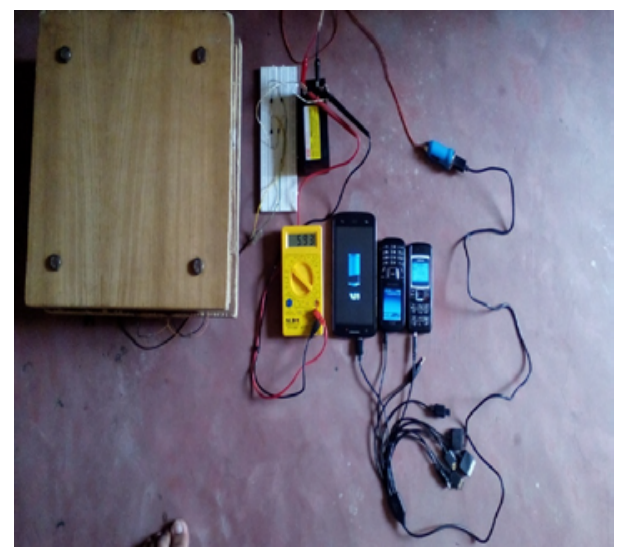

Figure 5: Connected allloads.

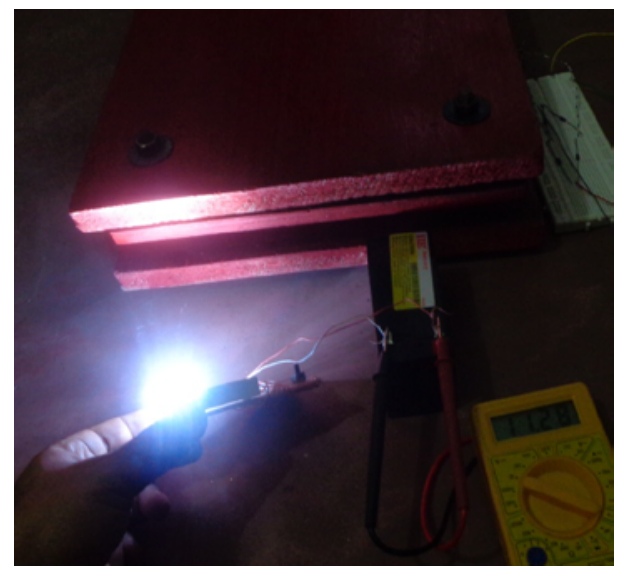

Figure 6: Connected a DC LED load.

\section{Conclusion}

The project is successfully tested which is the best economical, affordable energy solution to common people. This can be used for many applications in city areas where want more power. Bangladesh is a developing country where energy management is a big challenge for huge population. By using this project. I can drive D.C loads according to the force I applied on the piezo electric sensor. Although the theory developed in this report justifies the use of switching techniques in efficiently converting that energy to a usable form, there

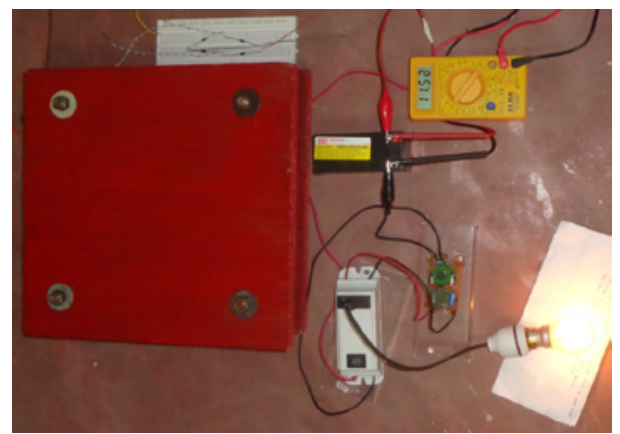

Figure 7: Connected a AC 5W bulb with inverter.

are obviously some practical limitations to the systems presented. The final prototype design does fulfill the objective of generating electricity from piezoelectric disk. Due to the low cost design of the piezoelectric system it is a practical product which could increase the operating period of most common products. The data collected is capable of extending the operational lifespan per charge of portable electronic devices.

Although the theory developed in this report justifies the use of switching techniques in efficiently converting that energy to a usable form, there are obviously some practical limitations to the systems presented. Measurements of source current into the primary and load current transferred from the secondary reveal that very little current gain truly occurs between the input and output ports of the switch in the forward converter hybrid. Further, similar results were encountered when one examines the energy transferred through the series switch and inductor in the buck converter. In addition, based on the results gathered in this investigation, the final prototype design does fulfill the objective of generating electricity from piezoelectric disk. Due to the low cost design of the piezoelectric system it is a practical product which could increase the operating period of most common products. The data collected is capable of extending the operational lifespan per charge of portable electronic devices.

\section{Discussion}

Bangladesh is a densely populated country. In Bangladesh, there are many regions where people are continuously travelling by walking. And these regions are always busy with people walking, which mean I can easily find the sources like vibration or pressure to produce electricity from piezoelectric material.

I created a mechanical structure for power generation. Inside that I placed a combination of many piezoelectric sensors. By pressing the structure the piezoelectric sensors will get the vibration and the sensors give electricity as output. After passing through a circuit the charge will store in the battery. I use two applications in our project. As I will place the model in a populated area, I can use this stored energy to light the passersby walking road without getting electricity from other sources. Another application is I can set a booth for charging mini power consumption devices which I use in our daily lives like mobile, iPod etc.

\section{References}

1. What is Piezo and Piezoelectricity (2013).

2. Diodes_bridge_rectifier.jpg (2004)

3. Foot step power generation wood panel.jpg (2013) 
Citation: Nayan HR (2015) Power Generation Using Piezoelectric Material. J Material Sci Eng 4: 171. doi:10.4172/2169-0022.1000171

Page 4 of 4

4. How piezoelectricity works.

5. Kymissis J, Kendall C, Paradiso JJ, Gershenfeld N (1998) Parasitic powe harvesting in shoes. Proc $2^{\text {nd }}$ IEEE Int Conf Wearable Computing. Los Alamitos, CA.

6. Glynne-Jones P, Beeby SP, White NM (2001) Towards a piezoelectric vibration- powered micro generator. IEEE Proc Sci Meas.Technol 148I: 68-72.

7. Engel TG (2000) Energy conversion and high power pulse production using Miniature piezoelectric compressors. IEEE Trans. Plasma Sci 28: 1338-1340.

8. Hugo Schmidt V (1992) Piezoelectric energy conversion in windmills pinprick Ultrasonics Symp 897-904. 